\title{
Extraction of flank wear growth models that correlates cutting edge integrity of ball nose end mills while machining titanium
}

\author{
K. Ramesh • Lim Beng Siong
}

Received: 23 December 2009/Accepted: 25 May 2010/Published online: 11 June 2010

(C) Springer-Verlag London Limited 2010

\begin{abstract}
The application of titanium alloys are increasingly seen at aerospace, marine, bio-medical and precision engineering due to its high strength to weight ratio and high temperature properties. However, while machining the titanium alloys using solid carbide tools, even with jet infusion of coolant lower tool life was vividly seen. The high temperatures generated at the tool-work interface causes adhesion of work-material on the cutting edges; hence, shorter tool life was reported. To reduce the high tool-work interface temperature positive rake angle, higher primary relief and higher secondary relief were configured on the ball nose end-mill cutting edges. However, after an initial working period, the growth of flank wear facilitates higher cutting forces followed by work-material adhesion on the cutting edges. Therefore, it is important to blend the strength, sharpness and surface integrity on the cutting edges so that the ball nose end mill would demonstrate an extended tool-life. Presently, validation of tool geometry is very tedious as it requires extensive machining experiments. This paper illustrates a new feature-based ball-noseend-mill-work interface model with correlations to the material removal mechanisms by which the tool geometry optimization becomes easier. The data are further deployed to develop a multi-sensory feature extraction/correlation model to predict the performance using wavelet analysis and Wagner Ville distribution. Conclusively, this method
\end{abstract}

\section{K. Ramesh $(\square)$}

Department of Mechanical Engineering,

University of Cape Town,

Rondebosch, South Africa

e-mail: Ramesh.Kuppuswamy@uct.ac.za

\section{B. Siong}

A*STAR Singapore Institute of Manufacturing Technology,

71, Nanyang Drive,

Singapore, Singapore enables to evaluate the different ball nose end mill geometry and reduces the product development cycle time.

Keywords Ball nose end mill · Tool geometry · Titanium • Machining

\section{Introduction}

The ongoing innovations in product development introduce components featured with complex profiles, miniature in size, thin walls and emerging materials. Such features create an acute need to monitor the machining behaviour and evolve optimum machining conditions. Therefore, new developments on real-time/process behaviour particularly in machining are continuously arising to establish prognostic monitoring, innovations in tool design and process optimisation. Prior studies were attempted on chip morphology, surface texture and cutting force signatures so as to establish the required tool geometry as well as cutting conditions [1-5]. Cutting tool features like rake angle and clearance angle are established on a broader scale for different materials. However, very little references are in the archive especially for cutting edge integrity. Past investigations mostly relate to extensive experiments that correlates flank wear against the cutting distance travelled. It should be noted that cutting edge conditions such as edge radius, surface integrity and cutting edge land predominantly decides the sharpness retention.

Machining of titanium and alloys impose serious challenges due to high cutting temperature, thin chips, poor heat conductivity, high cutting stresses and high strength even at elevated temperature [6, 7]. Furthermore, in titanium machining, the abnormal tool conditions generates accelerated flank wear, tool breakage and tool-work piece chatter. A force model was already developed that includes the effect of 
cutting edge polishing for titanium. Both experiments and the model suggests that cutting forces in the order of 20 to $50 \mathrm{~N}$ was induced while machining titanium alloys at cutting speed $=300 \mathrm{~m} / \mathrm{min}$, feed $/ \mathrm{rev}=0.075 \mathrm{~mm}$ and depth of cut $=$ $0.075 \mathrm{~mm}$ [8]. An attempt was made to use of liquid nitrogen as coolant in machining Ti-6Al-4V did increase the life of tool by 2.69 times against dry milling [9]. Machining of titanium at high speeds employs lower feed/tooth of value 0.025 to $0.04 \mathrm{~mm} /$ tooth and cutting speeds of value 200 to $400 \mathrm{~m} / \mathrm{min}$. It should be noted that in milling process feed/tooth can be equated to chip thickness. As the feed/tooth is small the effect of land, cutting edge radius and cutting edge surface integrity are the key factors that define the cutting tool behaviour. Most of the tool manufacturers perform polishing process on cutting edges to introduce fine radius in the order of 1 to $3 \mu \mathrm{m}$. As the process is a loose abrasive grinding type, definite control of radius is difficult. Therefore, process factors such as polishing time, stand-off distance and types of abrasive slurry are considered to impart the required cutting edge radius. Although the three parameters cutting edge radius, land and cutting edge integrity decides the tool-work interface behaviour, no previous work was reported especially for the ball nose end mill. Therefore, a model was developed to extract the tool-work interface feature and a suitable tool life was predicted for the selected tool geometry. This paper reports (1) feature extraction through experimental study of ball-noseend-mill-work interface, (2) tool geometry optimization and tool performance prediction for machining of Ti-6Al-4V alloy using ball nose end mill.

\section{Experimental set-up}

Experiments were conducted on a vertical machining centre (Kia VX460) (1) to establish the appropriate ball nose end mill geometry for machining titanium, (2) to predict the performance behaviour of a production run ball nose end mill through correlation of $\mathrm{AE}_{\mathrm{rms}}$ (acoustic emission) signal to wear behaviour. Shown in Fig. 1 is the mounting detail of: force transducer, vibration sensor and $\mathrm{AE}$ sensor. The force signals enable to understand the tool-work interface behaviour. Forces were measured in all three directions such as $F_{x}$, $F_{y}$ and $F_{z}$. A tapered work-piece surface measuring $60^{\circ}$ as shown in Fig. 1 was used for the machining experiments. The effective diameter of ball nose end mill is given in Eq. 1.

$d_{\mathrm{eff}}=2 \sqrt{d \cdot a_{p}-a_{p}^{2}}$

where $d_{\text {eff }}=$ effective tool diameter; $d=$ diameter of the ball nose end mill; $a_{p}=$ axial depth of cut

Four different ball nose end mills, geometries (see Fig. 2) were used for the experiments. Table 1 describes the major geometrical features of the tested ball nose end mills. The

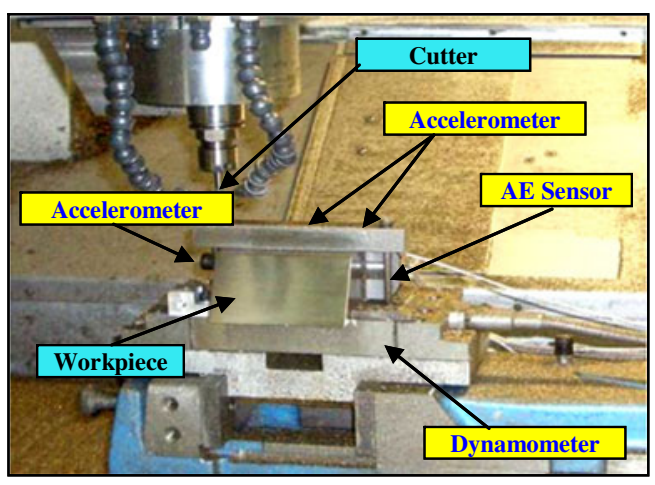

Fig. 1 Experimental set up of machining Ti-6Al-4V using various of ball nose end mill geometries

ball nose end mills produced in a $\mathrm{CNC}$ tool and cutter grinder undergoes polishing process in which the fine cutting edges are rounded off to 1 to $3 \mu \mathrm{m}$ so that the cutting edge integrity is maintained. The fine radius and land featured at the cutting edge distributes the cutting load and predominantly influences the tool life. However, the polishing process is a time-dependent process and parameters such as concentration of diamond paste, media, stand-off distance and velocity of media all influence the cutting-edge integrity. Furthermore, the process often results in chip off of the cutting edge and leads to scarp of cutting tools especially at the finishing stage. Therefore, the production always applies the polishing process for a shorter time resulting in a light cutting-edge treatment. On the other hand, properly treated ball nose end mills did demonstrate extended tool life.

\section{Analysis}

Shown in Fig. 3 is the feature extraction and feature correlation engines that are built using various signal analysis. The raw signals captured using force transducers and data acquisition system for four different tool geometries were further analysed.
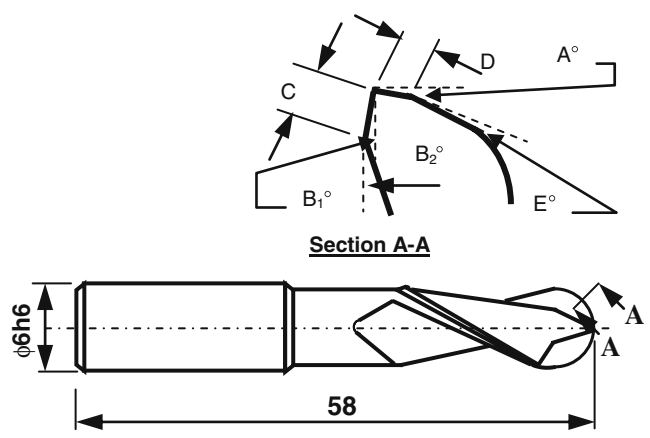

Fig. 2 Basic geometry of ball nose end mills used in the experiments: $A$ primary clearance angle; $B_{1} / B_{2}$ rake angle for the land $C$; $C$ land on the rake face; $D$ land on the primary angle, $E$ secondary clearance angle 
Table 1 Geometry of the ball nose end mills

\begin{tabular}{lllll}
\hline Ball nose end mill geometry & A & B & C & D \\
\hline Primary clearance angle $\left(\mathrm{A}^{\circ}\right)$ & $6^{\circ}$ & $9^{\circ}$ & $12^{\circ}$ & $10^{\circ}$ \\
Rake angle for the land $\mathrm{C}\left(\mathrm{B}^{\circ} 1 / \mathrm{B}^{\circ} 2\right)$ & $0^{\circ} / 10^{\circ}$ & $0^{\circ} / 10^{\circ}$ & $0^{\circ} / 10^{\circ}$ & $-3^{\circ} / 10^{\circ}$ \\
Land on the rake face C (mm) & - & - & - & $0.05 \sim 0.06$ \\
Land on the primary angle (D) $(\mathrm{mm})$ & 0.3 & 0.45 & 0.6 & 0.45 \\
Secondary clearance angle $\left(\mathrm{E}^{\circ}\right)$ & $18^{\circ}$ & $18^{\circ}$ & $21^{\circ}$ & $18^{\circ}$ \\
\hline
\end{tabular}

The following analysis was used to extract the appropriate signals that define the machining features for the respective ball nose end mill geometry.

\subsection{Signal analysis}

\section{- Time domain analysis}

Machining of titanium using a two-teeth (2T) ball nose end mill exhibits a periodic signal generation perturbed by spindle speed variation, tool conditions and the effect of chips. The ideal signal varies periodically with a frequency equal to the product of spindle speed and number of cutting edges. However, during the interaction of cutting edges on the work piece, either flank wear or adhesion of work-piece material on the cutting edge occurs resulting in a periodic random signal.

\section{- Frequency analysis}

To establish the optimum cutting conditions for the given machining situation, frequency analysis was done.

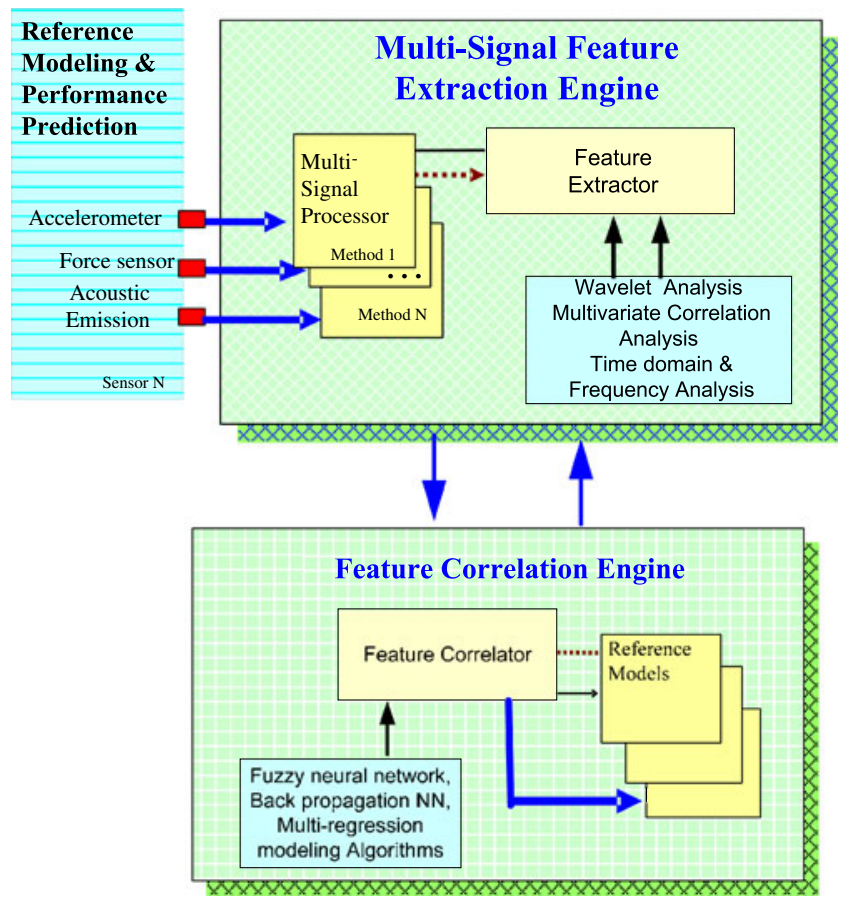

Fig. 3 Schematic of feature extraction and correlation models developed for evaluating the ball nose end mill geometry and performance prediction
The FFT analysis shows the frequencies for the captured signals, but it does not show how the frequency varies in time. So both frequency and time domain analysis of signals are important to establish the interface behaviour of cutting edges on the titanium.

\section{- Wavelet analysis}

Wavelet analysis enables to analyse the pattern of timefrequency spectrum of the process signals. This analysis overcomes the variation of signal intensity due to noise, shifts or other similar issues. The analysis uses the long intervals to find precise and low frequency information and shorter intervals to find the information on high frequency signals. If given, wavelet function is $\psi(t) \in L^{2}(R)$ wavelet are defined as per Eq. 2:

$\psi_{a b}(t)=|a|^{1 / 2} \psi\left(\frac{t-b}{a}\right)$

where "a" is a scaling factor, "b" is a shifting factor and $L^{2}(R)$ is the set of signals of finite energy.

A fast wavelet decomposition and reconstruction algorithm was previously reported [10]. Given a discrete sampling series $f(n)$ (where $n=1, \ldots . N$ ) of signal $f(t)$ and denoting the approximation vector of signal at scale $j=0$ as $C_{0}(n)=C_{j}(n)$ at $j=0=f(n)$; hence, the wavelet decomposition signal $f(t)$ can be written as:

$$
\begin{aligned}
& A_{j} f(t)=A_{j+1} f(t)+D_{j+1} f(t) \\
& \quad= \\
& \sum_{n} C_{J+1}(n) \varphi_{J+1, n}(t)+\sum_{n} D_{J+1}(n) \psi_{J+1, n}(t)
\end{aligned}
$$

$A_{j} f$ is the output of applying a low-pass filter to $f(t)$ and $D_{j} f$ is the output of applying a series of width-variable band pass filters to $f(t)$. The key point of wavelet analysis is to extract information from the original signal by decomposing it into a series of approximations and details as discussed over different frequency bands. Based on the relationship of frequency structure of wavelet decomposition, the detail of level and frequency bandwidth of approximation are $\left[\frac{1}{2} f_{s} 2^{-l}, \frac{1}{2} f_{s} 2^{-(l-1)}\right]$ and $\left[0, \frac{1}{2} f_{s} 2^{-l}\right]$, respectively. It should be noted that the frequency level of every band is decomposed into two equal sub-bands, and as 
Fig. 4 Cutting force $\left(F_{x}\right)$ behaviour of milling Ti6Al4V using different ball nose end mill geometry at cutting conditions: cutting speed $=40 \mathrm{~m} / \mathrm{min}$, feed/tooth $=40 \mu \mathrm{m}$, axial depth of cut $=0.2 \mathrm{~mm}$, radial depth of cut $=0.1 \mathrm{~mm}$

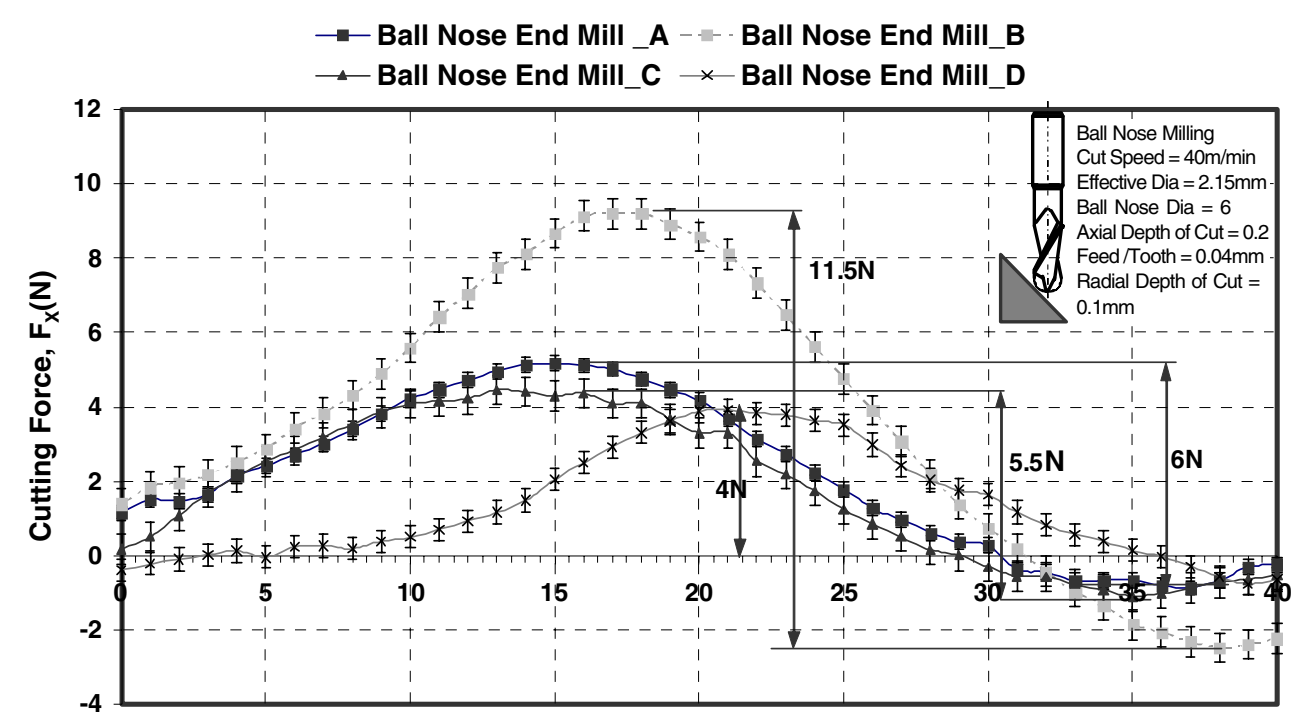

Time X0.01(Mill-Seconds) a result, the wavelet analysis enables to group the signals belonging to different frequency bands.

- Multivariate correlation analysis

To characterise the tool-wear interface features multiregression method was adopted in which the force signals, vibration signals and acoustic signals was used concurrently to understand the machining behaviour; hence, the performance is predicted.

\section{Results and discussion}

Shown in Figs. 4 and 5 are the cutting force signatures for four different micro-grain ball nose end mills featured with different geometries. The results suggest that peak forces $F_{x}(\mathrm{~N})$ generated for Ti-6Al-4V at cutting speed= $40 \mathrm{~m} / \mathrm{min}$, feed $/$ tooth $=40 \mu \mathrm{m}$, axial depth of cut $=0.2 \mathrm{~mm}$, radial depth of cut $=0.1 \mathrm{~mm}$ for geometries $\mathrm{A}, \mathrm{B}, \mathrm{C}, \mathrm{D}$ of ball nose end mill are 6, 11.5, 5.5 and $4 \mathrm{~N}$, respectively. At the same conditions, the process generated cutting forces $F_{z}(\mathrm{~N})$ for geometries $\mathrm{A}, \mathrm{B}, \mathrm{C}, \mathrm{D}$ of ball nose end mill around 4.6, 8, 5.2 and $3.75 \mathrm{~N}$, respectively. The results were analysed.

At every interaction of tool-work interface, the Ti-6Al$4 \mathrm{~V}$ work material undergoes stages of rubbing, ploughing and cutting by which chips are generated. Within the feed/ tooth movement of work-piece, the cutting force generated is experienced by a portion of rake face, cutting edge radius and to a certain extent the land on the primary relief angle.
Fig. 5 Cutting force $\left(F_{Z}\right)$ behaviour of milling Ti6Al4V using different ball nose end mill geometry at cutting conditions: cutting speed $=40 \mathrm{~m} / \mathrm{min}$, feed/tooth $=40 \mu \mathrm{m}$, axial depth of cut $=0.2 \mathrm{~mm}$, radial depth of cut $=0.1 \mathrm{~mm}$

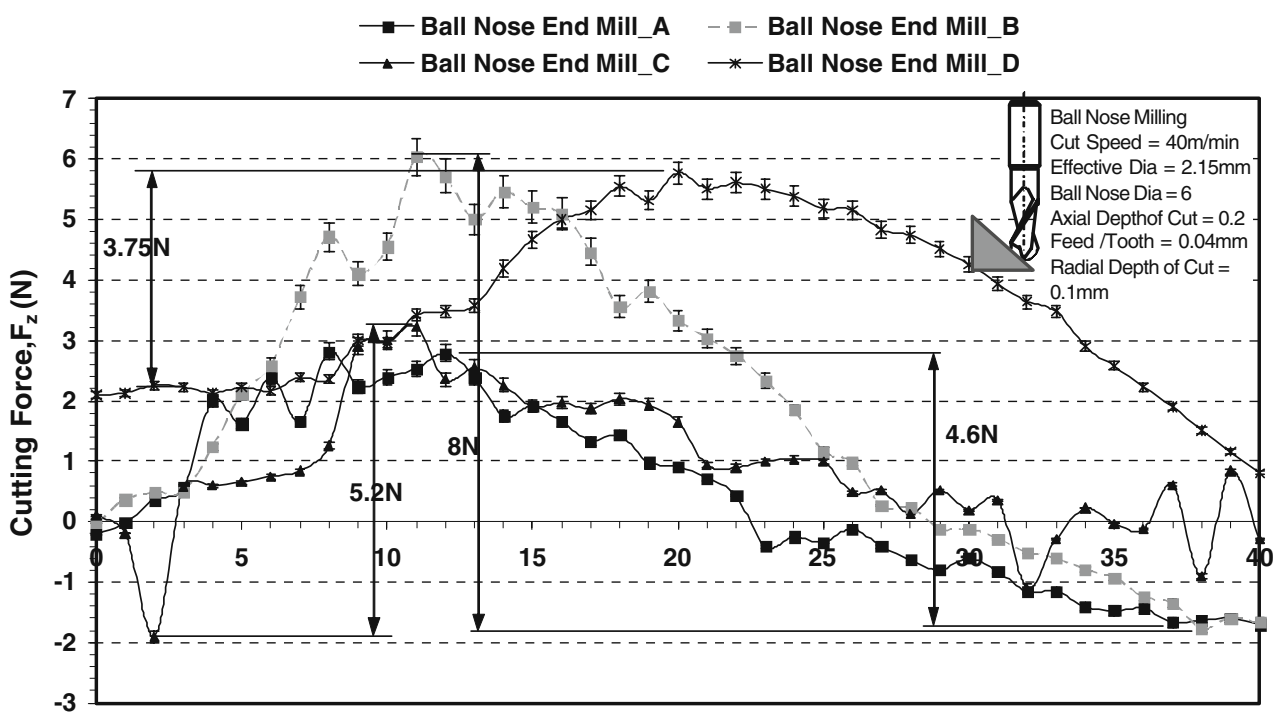

Time X0.01 (Milli-Seconds) 
Fig. 6 Underneath of chips produced by ball nose end mill geometry D and geometry A at cutting conditions: cutting speed $=40 \mathrm{~m} / \mathrm{min}$, feed/tooth $=40 \mu \mathrm{m}$, axial depth of cut $=0.2 \mathrm{~mm}$, radial depth of cut $=0.1 \mathrm{~mm}$
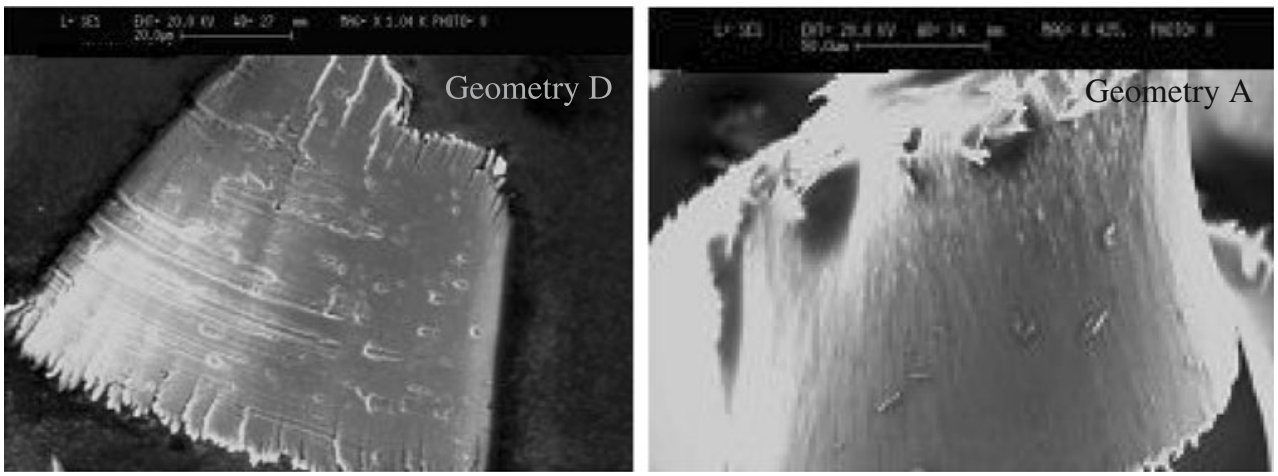

Geometries A to $\mathrm{C}$ are configured with positive rake angle $\left(10^{\circ}\right)$, primary relief angle $\left(6^{\circ}\right.$ to $\left.12^{\circ}\right)$, secondary relief angle $\left(18^{\circ}\right.$ to $\left.21^{\circ}\right)$ and cutting edge radius. Geometry D is designed to have negative rake angle of value $-3^{\circ}$ for $0.05 \sim 0.06 \mathrm{~mm}$ followed by positive rake angle $\left(10^{\circ}\right)$, primary relief angle $\left(10^{\circ}\right)$, secondary relief angle $\left(18^{\circ}\right)$ and cutting edge radius. It is well documented that ductile material require positive rake angle so that the chips glide on the rake face and curls to initiate the cracking mechanism [11]. Titanium offers high-specific cutting resistance which is around 2,180 2,400 $\mathrm{MPa}$ [12]. At the point of maximum chip cross-section, the cutting force distribution varies for different geometries depending upon the tool-work contact length. The maximum cutting force at the cutting edge is to be distributed on a cutting edge contact area of magnitude $1,600 \mu^{2}$ for geometry A to C and $1,800 \mu \mathrm{m}^{2}$ for geometry $\mathrm{D}$; hence, geometry D exhibits lower cutting force as shown in Figs. 4 and 5. Also, introduction of a minor negative rake angle followed by the positive rake angle for the ball nose end mill facilitates a sudden separation of chip flow by which adiabatic failure of chip formation mechanism is initiated. As a result of sudden separation of chips at the rake face land the chips produced for geometry D was found to be smaller than the geometry A. Also, underneath of chips produced by geometry D was found to be coarser than the geometry A. (see Fig. 6). Furthermore, it should be noted that computed specific cutting resistance for tool $\mathrm{A}, \mathrm{B}, \mathrm{C}$ and $\mathrm{D}$ varies from $100 \%, 178 \%, 117 \%$ and $82 \%$, respectively. Both lower specific cutting resistance and chip separation strategy results in consumption of less specific cutting energy which is clearly evident from the cutting force signatures shown in Figs. 4 and 5 and $\mathrm{AE}_{\mathrm{rms}}$ signals shown in Fig. 7. Also, the cutting edges shown in Fig. 8 for Geometry-D doubly confirm its integrity after cutting Ti-6Al-4V compared to geometries A, B and C.

\section{Surface finish}

To further validate the geometry of the ball nose end mill, surface finish of machined surface was measured after every $5 \mathrm{~m}$ of cutting distance. Shown in Fig. 9 is the typical surface trace produced by geometry-D periodically. It is
Fig. 7 Behaviour of $\mathrm{AE}_{\mathrm{rms}}$ signals while milling Ti6Al4V using different ball nose end mill geometry at cutting conditions: cutting speed $=40 \mathrm{~m} / \mathrm{min}$, feed/tooth $=40 \mu \mathrm{m}$, axial depth of cut $=0.2 \mathrm{~mm}$, radial depth of cut $=0.1 \mathrm{~mm}$

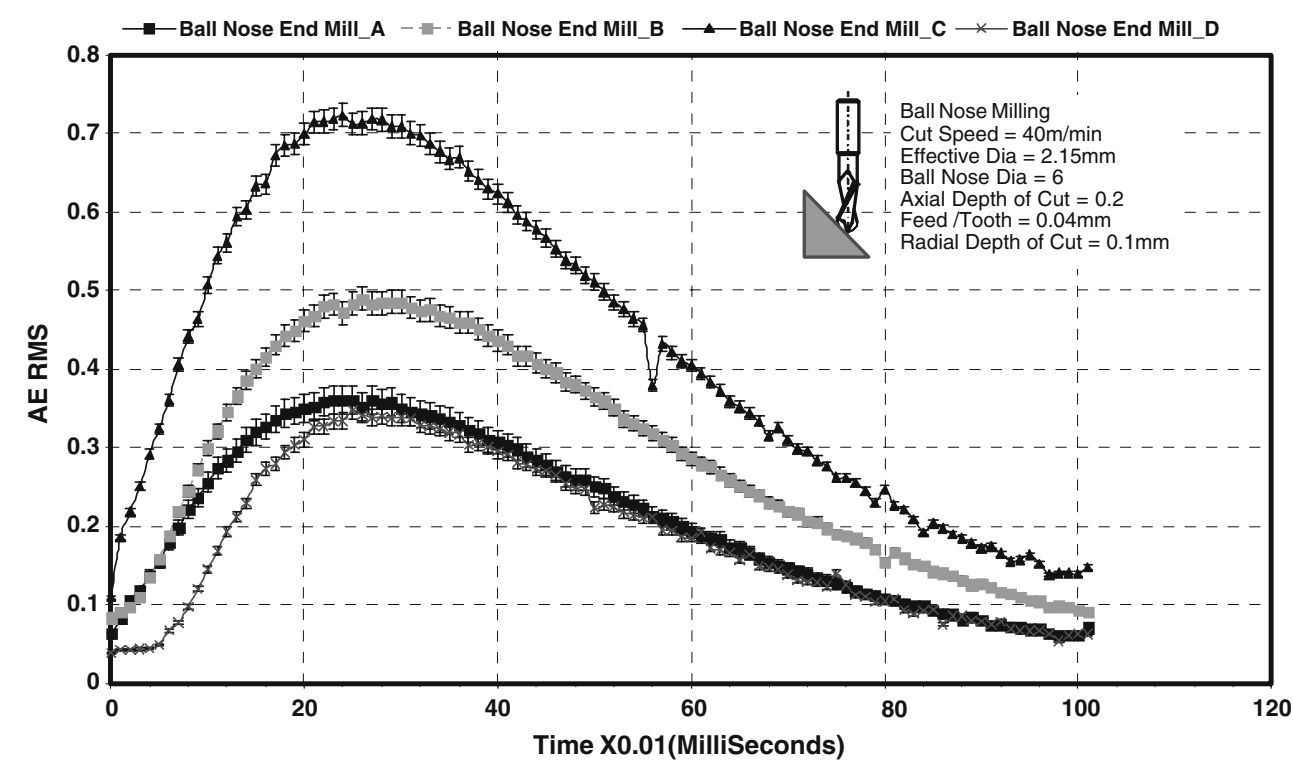


Fig. 8 Cutting edge wear behaviour for geometry $\mathbf{a}, \mathbf{b}, \mathbf{c}$ and $\mathbf{d}$ of ball nose end-mill at cutting conditions: cutting speed $=40 \mathrm{~m} / \mathrm{min}$, feed/tooth $=40 \mu \mathrm{m}$, axial depth of cut $=0.2 \mathrm{~mm}$, radial depth of cut $=0.1 \mathrm{~mm}$
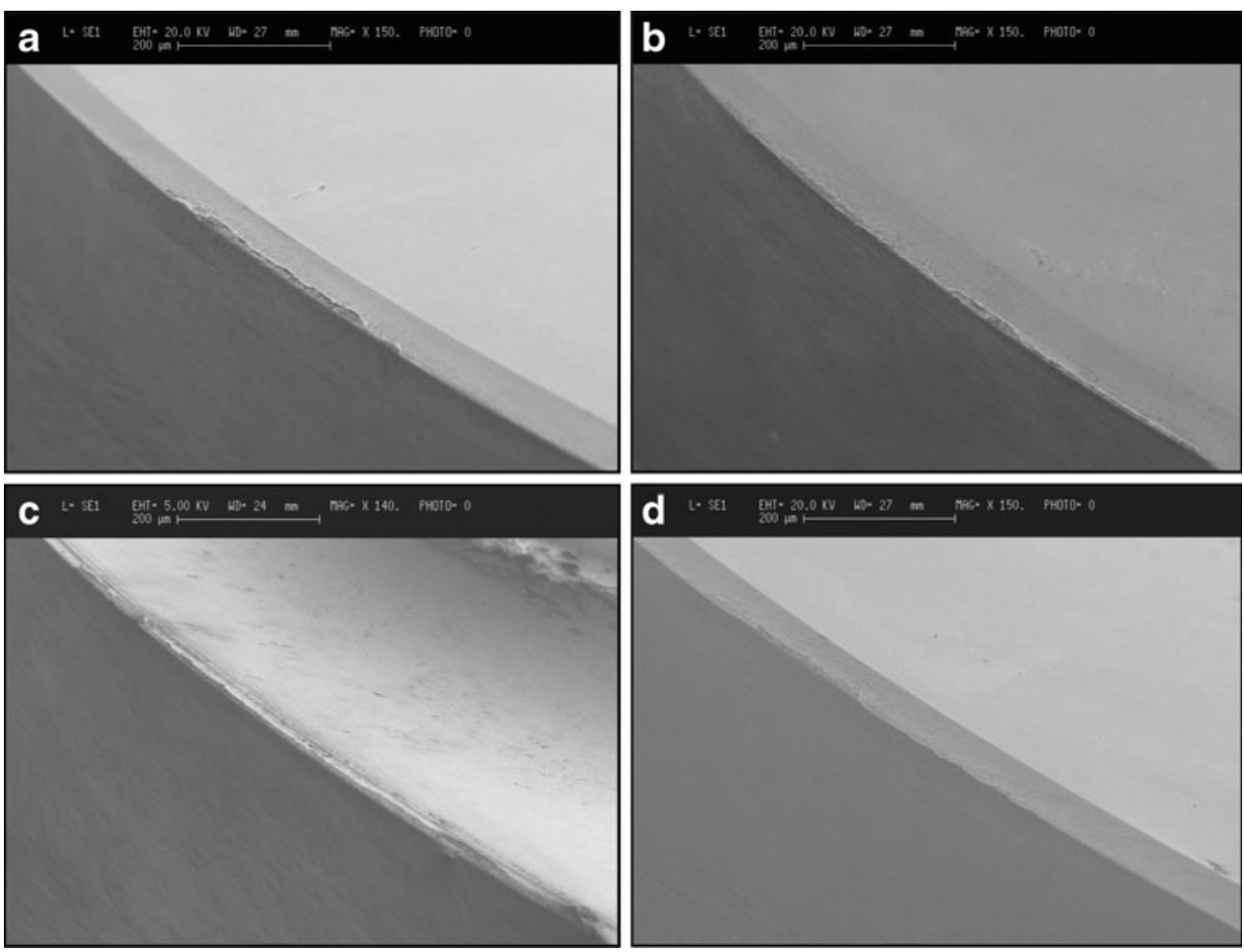

well documented that feed/tooth and edge radius predominantly influence the surface finish and the relationship is described in Eq. 5 [13]:

$R_{a}=\frac{v^{2}}{8 R_{n}}$

where $\nu=$ feed/tooth and $R_{n}=$ cutting edge radius. The experimental results also suggest that until the commencement of rapid flank wear, the surface finish $\left(R_{a}\right)$ was found to be within $0.8 \sim 1.0 \mu \mathrm{m}$. The experimental machining process did generate fine chips of size $0.6 \sim 0.8 \mathrm{~mm}$ indicating a true cutting action throughout the process. Furthermore, the end mills are mounted through hydraulic clamping on a rigid spindle of stiffness $250 \mathrm{~N} / \mu \mathrm{m}$. As a result of rigid machine tool, defined cutting edges and effective tool geometry, the surface finish results were consistent and remain within $0.8 \sim 1.0 \mu \mathrm{m}$ until the ball nose end mill reaches its end of life.
Fig. 9 Surface finish behaviour of ball nose end mill for geometry 4 on Ti6Al4V at conditions: cutting speed $=40 \mathrm{~m} / \mathrm{min}$, feed/tooth $=40 \mu \mathrm{m}$, axial depth of cut $=0.2 \mathrm{~mm}$, radial depth of cut $=0.1 \mathrm{~mm}$

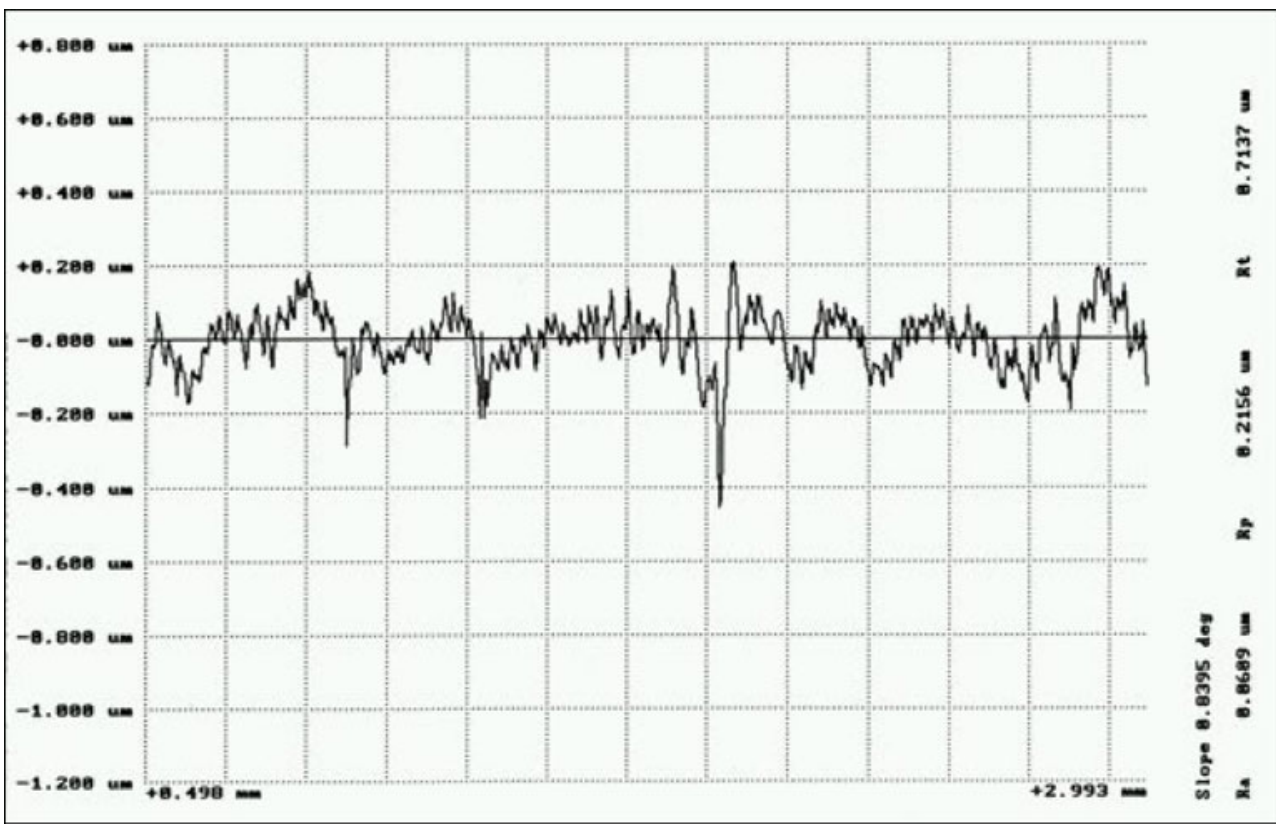


Fig. 10 Wear behaviour of ball nose end mill for geometry 4 on Ti6A14V at conditions: cutting speed $=40 \mathrm{~m} / \mathrm{min}$, feed/tooth $=40 \mu \mathrm{m}$, axial depth of cut $=0.2 \mathrm{~mm}$, radial depth of cut $=0.1 \mathrm{~mm}$

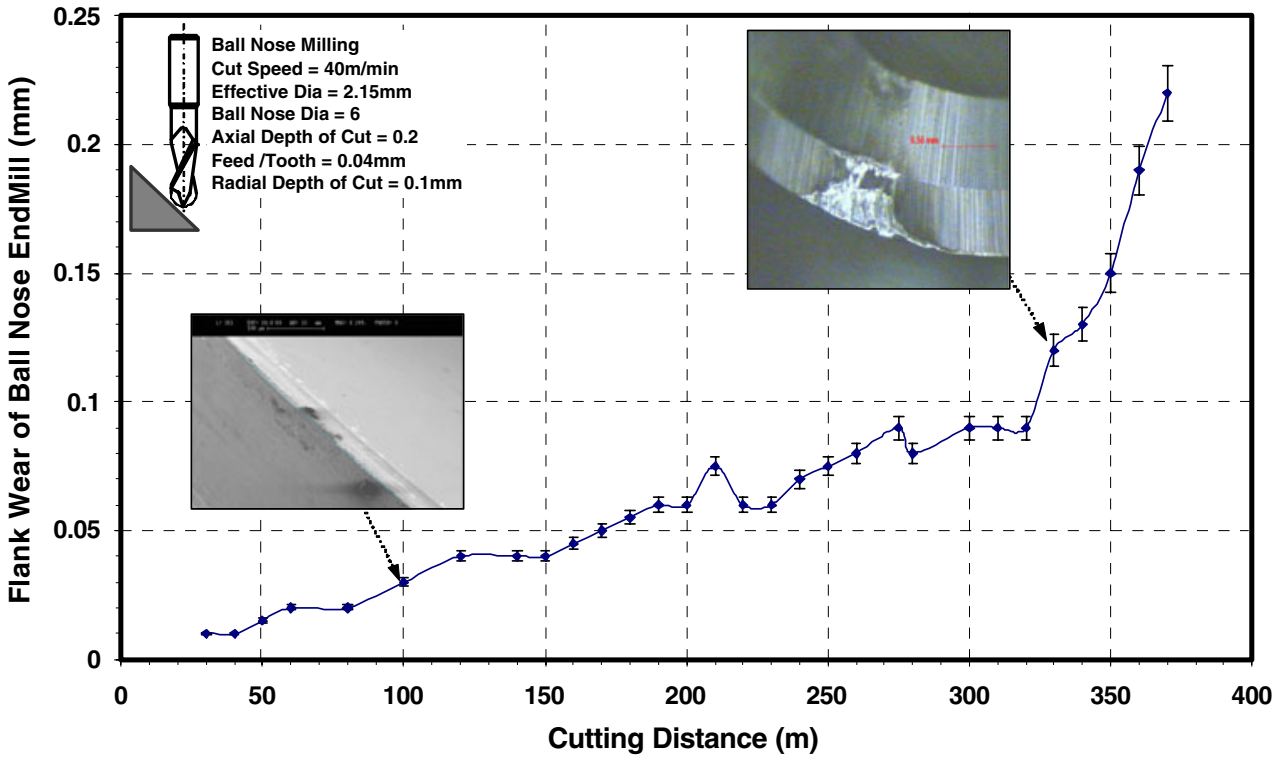

\section{Performance prediction}

Manufacturing of solid carbide ball nose end mill applies process such as parting, CG grinding, tool and cutter grinding, flute grinding and cutting edge polishing process. The polishing process often introduces chip off of cutting edge resulting in rejection of finished goods. The integrity of cutting edge depends upon several factors like residual stress-controlled grinding, ground surface texture and cutting edge radius formed at the polishing process. Such factors likely to vary from time to time due to continuously changing are grinding wheel topography, coolant conditions and results in process variation that severely affect the tool performance. Therefore, a method was devised to predict the cutter performance based on the test signals generated for a set of standard cutting conditions. To digitise the wear behaviour of ball nose end mills, $\mathrm{AE}_{\mathrm{rms}}$ signals was considered and compared with flank wear growth of ball nose end mills. Shown in Figs. 10 and 11 are the characteristics of flank wear and $\mathrm{AE}_{\mathrm{rms}}$ signals against cutting distance travelled, respectively. The experimental results suggest that the growth of flank wear of value 0.01 to $0.1 \mathrm{~mm}$ occurs linearly for $320 \sim 330 \mathrm{~m}$ of cutting distance followed by abrupt increase in the value. During the same cutting distance travel, the increase of $\mathrm{AE}_{\mathrm{rms}}$ signals was found to be linear of value 0.35 to 1 followed by a quick increase thereafter. Both results indicate a synergy between $\mathrm{AE}_{\mathrm{rms}}$ and flank wear; therefore, $\mathrm{AE}_{\mathrm{rms}}$ signal was used to predict the cutter performance through application of wavelet analysis. Prior to prediction, the
Fig. 11 Prediction and experimental validation of tool life for a ball nose end mill geometry 4 on Ti6Al4V at conditions: cutting speed $=40 \mathrm{~m} / \mathrm{min}$, feed/tooth $=40 \mu \mathrm{m}$, axial depth of cut $=0.2 \mathrm{~mm}$, radial depth of cut $=0.1 \mathrm{~mm}$

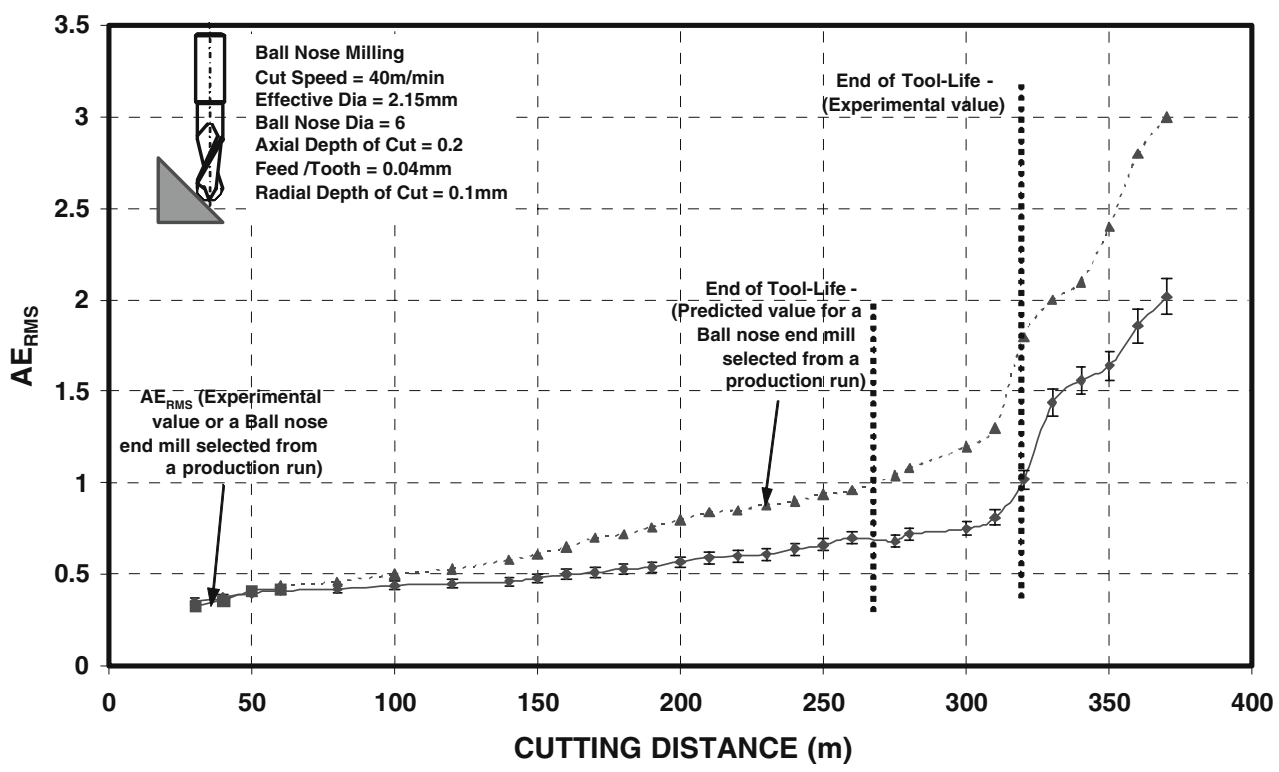


feature of wear behaviour was constructed using $\mathrm{AE}_{\mathrm{rms}}$ signals as given below;

In total, nearly 60,000 sets of data were captured under the cutting conditions: cutting speed $=40 \mathrm{~m} / \mathrm{min}$, feed $/$ tooth $=$ $40 \mu \mathrm{m}$, axial depth of cut $=0.2 \mathrm{~mm}$ and radial depth of cut $=$ $0.1 \mathrm{~mm}$. The data captured were separated into two sets: odd numbers that are used for training and even numbers for testing. The regression co-efficient obtained from the training data is given in Eq. 6 .

$$
\begin{aligned}
\mathrm{AE}_{\text {rms-wear }}= & -0.328-0.11 f_{m(t-1)}+0.105 f_{a(t-1)} \\
& +0.157 F_{a(t-1)}+0.11_{\operatorname{std}(t-1)}
\end{aligned}
$$

$T$ test was used to evaluate the significance of the regression co-efficient and $F$ test was used to test the overall significance of an observed multiple regression. The computed values of regression coefficient, $T$ test and $F$ test are

- $R^{2}=0.8759$

- $F$ test $=9,993.35$;

- $T \times 5 \%=1.645$

- $F \times 1 \%=3.02$

Both $T$ test and $F$ test value suggests that all the coefficients are statistically significant at $5 \%$ and $1 \%$ acceptance levels, respectively. The results are also cross-checked with physical measurement of flank wear after every $5 \mathrm{~m}$ of cutting distance and shown in Fig. 10. Upon manufacturing of ball nose end mill, a test tool from every production run is taken and $\mathrm{AE}_{\mathrm{rms}}$ signals are captured for a small period. The results are plotted to predict using the template created after extensive signal capturing and wear measurement experiments. The growth of wear was seen by abrasive and fine scouring marks on the flank which indicate predominance of mechanical loads and thus confirm significant presence of abrasive wear (see in Fig. 10). Between 30 and $60 \mathrm{~m}$ of cutting distance $\mathrm{AE}_{\text {rms }}$ test signals of magnitude 0.33 to 0.42 was measured and shown in Fig. 11. The short experiment results were further extrapolated using the $\mathrm{AE}_{\mathrm{rms}}$ wear model given in Eq. 6. The prediction results using test $\mathrm{AE}_{\mathrm{rms}}$ signals and extrapolation suggests that the test tool would last for $270 \sim 280 \mathrm{~m}$ of cutting distance due to process variation of cutting edge formations. It should be noted that the tool-work interface is a complex phenomenon generating adhesion wear or abrasive wear or combination of both and hence it is important to apply the same conditions for establishing the birth characterization of a new ball nose end mill.

\section{Conclusions}

In this paper, a new ball nose end mill geometry that demonstrates lower cutting force and flank wear growth is presented. The geometry predominantly emphasises the significance of cutting edge integrity such as cutting edge radius, surface texture and land on the primary relief angle. The ball nose end mills featured with a short negative rake angle of value $-3^{\circ}$ for $0.05 \sim 0.06 \mathrm{~mm}$ followed by positive rake angle of value $10^{\circ}$ applies lower cutting forces signatures for machining Ti-6Al-4V. For the selected geometry of the ball nose end mills, $\mathrm{AE}_{\mathrm{rms}}$ signals and flank wear characteristics were correlated. $\mathrm{AE}_{\mathrm{rms}}$ signals were used to predict the performance of ball nose end mills produced in every batch of production run. The output enabled to classify the ball nose end mills into groups such as high performance and standard so that the ball nose end mills were priced in close relation with the expected performance.

Acknowledgement The authors wish to thank Dr. Li X of Singapore Institute of Manufacturing Technology (SIMTech) and Mr. Roger Heng of Alignment Tool (Singapore) Pte Ltd for providing the logistics support towards project execution.

\section{References}

1. Bouzakis KD, Aichouh P, Efstathiou K (2003) Determination of the chip geometry, cutting force and roughness in free form surfaces finishing milling with ball end tools. Int $\mathrm{J}$ Mach Tools Manuf 43:499-514

2. Kaldor S, Ber A, Technion/Haifa (1990) "A criterion to optimize cutting tool geometry". Ann CIRP 31(1):53-56

3. Wang ZG, Rahman M, Wong YS (2005) Tool wear characteristics of binderless cbn tools used in high-speed milling of titanium alloys. Wear 258:752-758

4. Milfelner M, Cus F, Balic J (2005) An overview of data acquisition system for cutting force measuring and optimization in milling. J Mater Process Technol 164-165:1281-1288

5. Dolinsek S, Kopac J (1999) Acoustic emission signals for tool wear identification. Wear 225-229:295-303

6. Rahman M, Wong YS, Zareena AR (1997) Machinability of titanium alloys. JSME Int J 46(1):107-115

7. Ezugwu EO, Bonney J, Yamane Y (2003) An overview of the mach inability of aero-engine alloys. J Mater Process Technol 134:233-253

8. Wang ZG, Rahman M, Wong YS, Li XP (2005) "A hybrid cutting force model for high-speed milling of titanium alloys". CIRP Ann Manuf Technol 54(1):71-74

9. Su Y, He N, Li L, Li XL (2006) An experimental investigation of effects of cooling/lubrication conditions on tool wear in high speed end milling of Ti-6Al-4V. Wear 261:760-766

10. Mallet S (1989) "A theory for multi-resolution signal decomposition: the wavelet representation". IEEE Trans Pattern Anal Mach Intell 11(7):674-693

11. Shaw MC (2004) Metal cutting principles - a book, 3rd revised edition. MIT, Boston

12. Zeman P, Madi J (2008) "Milling of Ti-6Al-4 V Alloy with Cemented Carbide Tools", Proceedings of the 3 rd International Conference on Manufacturing Engineering (ICMEN), 1-3 October. Chalkidiki, Greece

13. Anon A (2006) Carbide end mills portfolio. Catalogue of Alignment Tool (S) Pte Ltd, Singapore 